Bài báo khoa học

\title{
Nghiên cứu xây dựng bộ chỉ tiêu nhiệt ẩm ảnh hưởng tới sức khỏe một số cộng đồng dân cư tại Quảng Nam
}

\author{
Nguyễn Công Tài ${ }^{1}$, Nguyễn Đăng Quang ${ }^{2}$ \\ 1 Đài khí tượng thủy văn tỉnh Quảng Nam; taikttvqnam@gmail.com \\ 2 Trung tâm Ứng dụng công nghệ khí tượng thủy văn; quangvnes@gmail.com \\ * Tác giả liên hệ: taikttvqnam@gmail.com; Tel.: +84-963315886
}

Ban Biên tập nhận bài: 25/7/2020; Ngày phản biện xong: 20/8/2020; Ngày đăng bài: $25 / 9 / 2020$

Tóm tắt: Nghiên cứu này đánh giá xu thế biến đổi nhiệt độ cảm nhận $(\mathrm{HI})$ và xu thế biến đổi hệ số nhiệt dư thừa (EHF) thông qua dữ liệu khí tượng tại Quảng Nam từ năm 1979 đến 2019. Kết hợp với số liệu y tế tại địa phương, ngưỡng nhiệt độ-độ ẩm ảnh hưởng tới sức khỏe một số cộng đồng dân cư tại Quảng Nam được phân cấp, xác định. Đây là một trong những nghiên cứu đầu tiên ở Việt Nam theo hướng ứng dụng thông tin thời tiết để chăm sóc, phục vụ sức khỏe cộng đồng.

Từ khóa: Nhiệt độ cảm nhận (Heat Index); Hệ số nhiệt dư (Excess Heat Factor); Nắng nóng nguy hiểm (Heatwave).

\section{Mở đầu}

Trong quá trình tồn tại, con người điều hòa thân nhiệt thông qua cơ chế làm mát bay hơi khi nhiệt độ không khí cao hoặc độ ẩm thấp. Nghĩa là khi thân nhiệt nóng lên, cơ thể sẽ bài tiết mồ hôi, mồ hôi bốc hơi sẽ làm giảm nhiệt độ trên bề mặt cơ thể; đây được coi là hệ thống làm mát tự nhiên của con người. Tuy nhiên, trong điều kiện nóng và ẩm, hiệu quả điều hòa thân nhiệt chậm lại và cơ thể không thể duy trì nhiệt độ ổn định. Chính vì thế, sự kết hợp của nắng nóng và độ ẩm cao trong nhiều trường hợp là mối nguy hại đối với sức khỏe con người.

Cho đến nay, trên thế giới đã có nhiều công trình nghiên cứu về vấn đề này, [1] đã xây dựng phương trình tính chỉ số nhiệt từ phương pháp hồi quy đa biến; Cơ quan quản lý khí quyển và đại dương Hoa Kỳ (NOAA) đã sử dụng phương trình trong nghiên cứu [1] xây dựng các ngưỡng $\mathrm{HI}$ cảnh báo cho cộng đồng. Một nghiên cứu khác [2] tại Cơ quan khí tượng Úc đã nghiên cứu đề xuất hệ số nhiệt dư thừa EHF (Excess Heat Factor) để theo dõi và đánh giá hiện tượng nắng nóng nguy hiểm-hiện tượng nắng nóng xảy ra trong ít nhất ba ngày liên tiếp và đạt mức phân vị $90 \%$ (heatwave). Một số nghiên cứu khác [3] đánh giá stress nhiệt dựa trên chỉ số nhiệt độ bầu ướt TW tại vùng Nam Ả. Eun-Soon xem xét tác động của nhiệt độ và độ ẩm tương đối đối với stress nhiệt trên cơ sở tập hợp các mô phỏng biến đổi khí hậu (BĐKH) có độ phân giải cao để dự tính mức độ stress nhiệt ở vùng Nam Á. Kết quả cho thấy nhiều vùng Nam Á vượt quá ngưỡng nhiệt độ bầu ướt cho phép vào cuối thế kỷ 21 . Khu vực có mức độ stress nhiệt cao nhât là xung quanh các vùng nông nghiệp đông dân cư ở lưu vực sông Hằng và sông Ấn ở khu vực Nam Á. Nghiên cứu khác [4] đã đánh giá stress nhiệt dựa trên chỉ số nhiệt độ hiệu dụng ET thông qua việc đánh giá tác động của nhiệt độ, độ ẩm tương đối và tốc độ gió trên toàn lãnh thổ Trung Quốc. Kết quả cho thấy stress nhiệt xảy ra từ tháng 12 đến tháng 2 và từ tháng 6 đến tháng 8 trong năm. Sự gia tăng stress nhiệt chủ yếu gây ra do nhiệt độ và tốc độ gió trong khi độ ẩm tương đối ảnh hưởng không đáng kể. 
Trong nước, một số chương trình, công trình nghiên cứu liên quan tới chủ đề này cũng đã được thực hiện trong thời gian vừa qua. Cụ thể như nghiên cứu về stress nhiệt đối với người lao động trong bối cảnh $\mathrm{B} Đ K H$ tại Đà Nẵng [5]. Để tiến hành nghiên cứu nhóm tác giả đã sử dụng chuỗi số liệu từ năm 1970-2011 để phân tích các xu hướng về nhiệt độ ngày và đêm từ đó dự tính sự biến đổi của stress nhiệt trong tương lai. Kết quả cho thấy nhiệt độ ban đêm quá cao sau những ngày nắng nóng khiến công nhân không thể phục hồi và dẫn đến dễ gặp stress nhiệt. Một nghiên cứu khác [6] đánh giá tác động của biến đổi khí hậu tới sức khỏe cộng đồng tại huyện Giao Thủy, tỉnh Nam Định và đề xuất giải pháp thích ứng. Nghiên cứu này đã tiến hành phân tích diễn biến một số bệnh dịch có liên quan đến biến đổi khí hậu bằng cách sử dụng mô hình tương quan, hồi quy tuyến tính đơn biến, các dữ liệu đầu vào bao gồm nhiệt độ, lượng mưa, độ ẩm và một số bệnh dịch phục vụ cho nghiên cứu. Kết quả nghiên cứu cho thấy diễn biến của một số bệnh có tương quan với sự thay đổi của thời tiết. Gần đây nhất, năm 2019 đề tài nghiên cứu [7] đã nghiên cứu xác định bộ chỉ tiêu và xây dựng mô hình khí hậu phục vự cảnh báo nguy cơ phát sinh dịch bệnh trên người ở một số tỉnh vùng miền núi phía Tây Bắc. Sử dụng mô hình phân bố độ trễ phi tuyến tính (distributed lag nonlinear model-DLNM) để phân tích tác động giữa tỷ lệ số ca bệnh với nhiệt độ, lượng mưa, độ ẩm không khí theo các bước trễ thời gian. Kết quả là các tác giả đã xây dựng được bộ chỉ tiêu khí hậu liên quan đến nguy cơ phát sinh một số dịch bệnh phổ biến đối với sức khỏe con người ở một số tỉnh vùng miền núi phía Bắc (Sơn La, Điện Biên, Lai Châu).

Qua việc tóm tắt một số nghiên cứu tiêu biểu trong và ngoài nước nêu trên nhận thấy vấn đề nghiên cứu về mối liên hệ giữa một số điều kiện thời tiết nguy hiểm và sức khỏe cộng đồng chưa được thực hiện ở Quảng Nam. Đây chính là một trong những động lực để thực hiện nghiên cứu này. Mục 2 của bài báo giới thiệu về khu vực nghiên cứu, loại dữ liệu và phương pháp nghiên cứu; Mục 3 giới thiệu các kết quả nghiên cứu và một số luận điểm để thảo luận; cuối cùng Mục 4 được dành cho các Kết luận của nghiên cứu này.

\section{Phương pháp nghiên cứu}

\subsection{Khu vưc nghiên cúu}

Khu vực nghiên cứu tại thành phố Tam Kỳ thuộc tỉnh Quảng Nam, thành phố Tam Kỳ có địa hình vùng đồng bằng duyên hải, là vùng chuyển tiếp từ dạng đồi núi cao phía Tây, thấp dần xuống sang phía Đông. Địa hình có dạng đồi thấp, và đồng bằng được hình thành do bồi tích sông, biển và quá trình rửa trôi, toàn khu vực bị chia cắt nhiều bởi các sông, suối thuộc lưu vực của sông Trường Giang.

Là địa phương nằm trong khu vực có khí hậu nhiệt đới gió mùa nên có nền nhiệt độ và độ ẩm tương đối cao. Nhiệt độ và độ ẩm tương đối trong năm có sự thay đổi theo hoạt động của gió mùa, từ tháng 10 cho đến tháng 3 năm sau do chịu ảnh hưởng chủ yếu của gió mùa Đông Bắc nên nền nhiệt độ trung bình duy trì từ $21,0-26,0^{\circ} \mathrm{C}$, độ ẩm trung bình dao động từ 85-90\%. Từ tháng 4 đến tháng 9 hằng năm gió mùa Tây Nam hoạt động kết hợp với hiệu ứng phơn của địa hình nên nền nhiệt độ khá cao, tháng 4-9 hằng năm nhiệt độ trung bình tháng dao động từ $27,0-29,0{ }^{\circ} \mathrm{C}$, độ ẩm tương đối trung bình từ $75-85 \%$.

Trung bình hằng năm có $49-51$ ngày có nhiệt độ $\geq 35^{\circ} \mathrm{C}$, năm có số ngày xuất hiện nhiệt độ $\geq 35^{\circ} \mathrm{C}$ nhiều nhất là 103 ngày năm 2019 ; và trung bình có $6-13$ ngày có nhiệt độ $\geq 37$ ${ }^{\circ} \mathrm{C}$, nhiều nhất là 50 ngày năm 2019 . Nhiệt độ ngày cao nhất lên tới $41,0{ }^{\circ} \mathrm{C}(01 / 7 / 2015)$.

\subsection{Dũ liệu}

Dữ liệu khám chữa bệnh sử dụng trong nghiên cứu là dữ liệu bệnh nhân khám chữa bệnh tại ba bệnh viện (Bệnh viện đa khoa tỉnh Quảng Nam, Bệnh viện phụ sản nhi Quảng Nam, và Bệnh viện đa khoa thành phố Tam Kỳ) thời kỳ 2017-2019. Thông tin số lượng người khám chữa các bệnh hô hấp, tim mạch, cao huyết áp, hen suyễn, sốt, sốt xuất huyết, đột quỵ ... và được chọn lọc theo các mã A90-A99, I10-I15, I20-I28, I30-I52, I60-I69, J00-J06, 
J09-J18, J20-J22, J30-J39, J40-J47, J60-J70, J80-J84, J85-86, J90-J94, J95-J99 (Bảng tra ICD-International Classification of Diseases-Phân loại thống kê Quốc tế về các bệnh tật và vấn đề sức khỏe liên quan trên toàn cầu, gọi tắt là Phân loại quốc tế về bệnh tật).

Dữ liệu khí tượng bao gồm nhiệt độ trung bình $\left({ }^{\circ} \mathrm{C}\right)$ và độ ẩm tương đối trung bình $(\%)$ ngày thời kỳ 1979-2019 tại hai trạm khí tượng Tam Kỳ và Trà My. Riêng đối với trạm Tam Kỳ, số liệu nhiệt độ tối cao, tối thấp ngày cũng được thu thập và sử dụng (1979-2019); đặc biệt trong mười năm gần đây (2010-2019) số liệu tự động ồn định nên cũng đã thu thập và sử dụng cả số liệu giờ của nhiệt độ và độ ẩm tương đối.

\subsection{Phưong pháp xây dựng bộ chỉ tiêu nhiệt ẩm ảnh hưởng tới sức khỏe}

Nhiệt độ cảm nhận HI (Heat Index) được xác định bởi phương trình hồi quy đa biến do Lans P. Rothfusz đề xuất năm 1990.

$$
\begin{aligned}
& \mathrm{HI}=-42.379+(2.04901523 * \mathrm{~T})+(10.14333127 * \mathrm{Rh})-(0.22475541 * \mathrm{~T} * \mathrm{Rh})- \\
& \left(0.00683783 * \mathrm{~T}^{2}\right)-\left(0.05481717 * \mathrm{Rh}^{2}\right)+\left(0.00122874 * \mathrm{~T}^{2 *} \mathrm{Rh}\right)+ \\
& \left(0.00085282 * \mathrm{~T}^{*} \mathrm{Rh}^{2}\right)-\left(0.00000199 * \mathrm{~T}^{2} * \mathrm{Rh}^{2}\right)
\end{aligned}
$$

Trong đó $\mathrm{T}$ là nhiệt độ (độ $\mathrm{F}$ ) và Rh là độ ẩm tương đối (\%).

Để tính được $\mathrm{HI}$ cần có số liệu nhiệt độ và độ ẩm cùng thời gian để tính toán. Tuy nhiên do thời gian từ năm 2010 trở về trước việc đo đạc số liệu khí tượng từng giờ khó khăn nên số liệu trung bình ngày được sử dụng để tính HI trung bình từ năm 1979-2019.

Từ năm 2010 đến nay thì số liệu giờ tương đối đầy đủ. Trong nghiên cứu này đã thử nghiệm tính HI tại tất cả các giờ trong năm 2019, kết quả thu được cho thấy chỉ số nhiệt độ cảm nhận đạt giá trị lớn nhất ngày ở các tháng hầu như dao động từ 11 đến 16 giờ, và giá trị nhiệt độ cảm nhận lúc 13 giờ cũng gần với giá trị lớn nhất. Do đó nhiệt độ và độ ẩm lúc 13 giờ được sử dụng để tính toán chỉ số $\mathrm{HI}$ và đánh giá xu thế biến đổi của chỉ số này trong thời gian từ 2010-2019.

Hệ số nhiệt dư EHF (Excess Heat Factor) được đề xuất [2]. Bộ chỉ số này dùng để theo dõi và phân loại cường độ "nắng nóng nguy hiểm-heatwave"; trong nghiên cứu này đề xuất sử dụng thuật ngữ "nắng nóng nguy hiểm" để mô tả hiện tượng "heatwave" hiện tượng nhiệt độ cao ở mức phân vị 90\% trở lên. Nhiệt dư (EHIsig) chịu sự chi phối bởi nhiệt độ trung bình trong ba ngày liên tiếp và sự thích nghi $(E H I a c c)$ của cơ thể người với chuỗi nhiệt độ trong 30 ngày trước đó. Điểm khác biệt của nghiên cứu này với nghiên cứu của Nairn và Fawcett là chúng tôi sử dụng phân vị 90 so với phân vị 95.

$$
\mathrm{EHI} \text { sig }=\left(\mathrm{T}_{\mathrm{i}}+\mathrm{T}_{\mathrm{i}+1}+\mathrm{T}_{\mathrm{i}+2}\right) / 3-\mathrm{T}_{90}\left({ }^{\circ} \mathrm{C}\right)
$$

Với $\mathrm{Ti}=\left(\mathrm{T}_{\max }+\mathrm{T}_{\min }\right) / 2, \mathrm{~T}_{90}$ là phân vị thứ 90 của $\mathrm{T}_{\mathrm{i}}$

$$
\begin{gathered}
\text { EHI accl }=\left(\mathrm{T}_{\mathrm{i}}+\mathrm{T}_{\mathrm{i}+1}+\mathrm{T}_{\mathrm{i}+2}\right) / 3-\left(\mathrm{T}_{\mathrm{i}-1}+\ldots+\mathrm{T}_{\mathrm{i}-30}\right) / 30\left({ }^{\circ} \mathrm{C}\right) \\
\mathrm{EHF}=\mathrm{EHI} \operatorname{sig} \times \max (1, \mathrm{EHI} \text { accl })\left({ }^{\circ} \mathrm{C}^{2}\right) .
\end{gathered}
$$

Nghiên cứu này sử dụng phần mềm ClimPACT2 để tính toán, đánh giá một số chỉ số (trong đó có $\mathrm{EHF}$ ) để nghiên cứu hiện tượng nắng nóng nguy hiểm đối với sức khỏe cộng đồng tại Quảng Nam. ClimPACT2 được viết trên ngôn ngữ R, đây là phần mềm mã nguồn mở (https://github.com/ARCCSS-extremes/climpact2).

Ngoài phương pháp thống kê thực nghiệm nêu trên, phương pháp thống kê vật lý được sử dụng để đánh giá xu hướng biến đổi HI và nắng nóng nguy hiểm từ năm 1979-2019; qua đó tìm mối liên hệ giữa $\mathrm{HI}$ và nắng nóng nguy hiểm. Tương tự, số lượng bệnh nhân khám chữa bệnh có triệu chứng liên quan tới thời tiết nắng nóng trong giai đoạn 2017-2019 cũng được tiến hành phân tích, đánh giá trong bài báo này.

\section{Kết quả và thảo luận}

\subsection{Xu thế biến đổi nhiệt độ cảm nhận giai đoạn 1979-2019}


Trong thời gian gần đây chỉ số nhiệt cảm nhận trung bình trong các năm có xu hướng dao động mạnh hơn, cụ thể nhiệt độ cảm nhận trung bình trong thời gian gần đây thường xuyên vượt ngưỡng giá trị thấp nhất hoặc cao nhất (Hình 1).

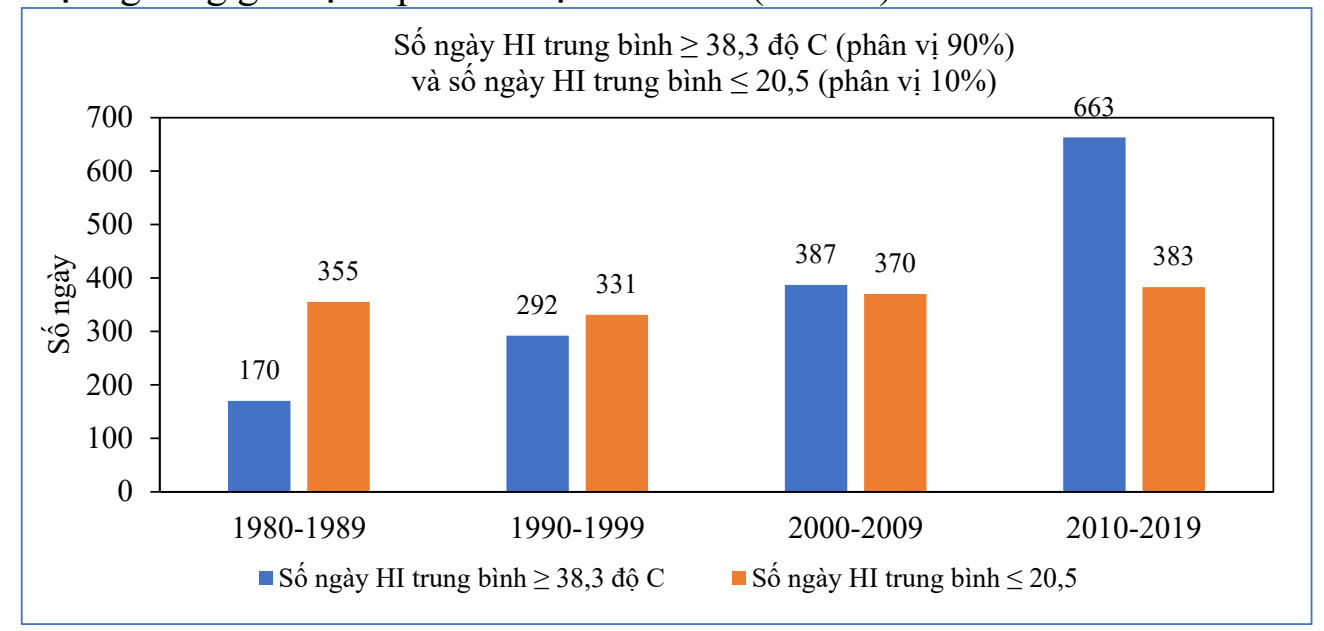

Hình 1. Nhiệt độ cảm nhận (HI) trung bình từ 1980-2019.

Tính toán tất cả các giờ trong từng ngày của năm 2019 (Hình 2) cho thấy chỉ số nhiệt độ cảm nhận đạt giá trị lớn nhất ngày ở các tháng hầu như dao động từ 11 đến 16 giờ, và giá trị nhiệt độ cảm nhận lúc 13 giờ cũng gần với giá trị lớn nhất.
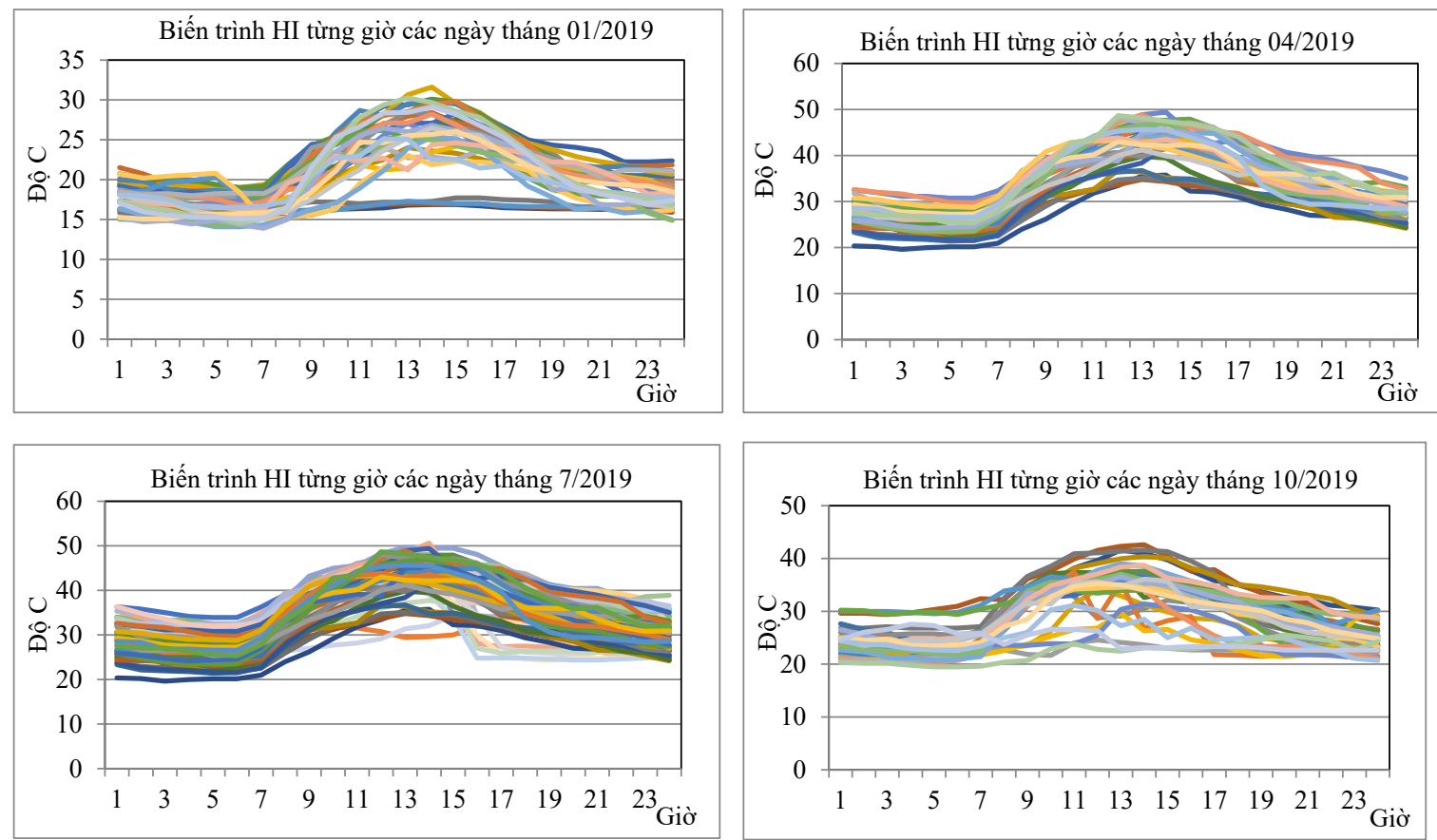

Hình 2. Nhiệt độ cảm nhận HI của bốn tháng đại diện trong năm 2019.

Tại Mỹ, NOAA sử dụng hai ngưỡng cơ bản là $32,8^{\circ} \mathrm{C}$ và $39,4^{\circ} \mathrm{C}$ để cảnh báo nguy hiểm tới người dân. Vấn đề là chúng ta cần đánh giá hai ngưỡng giá trị này liệu có thể được áp dụng đối với người dân địa phương ở Quảng Nam hay không? Số liệu tại Quảng Nam cho thấy, với ngưỡng $\mathrm{HI} \geq 39,4^{\circ} \mathrm{C}$ từ tháng 4-9 thì số ngày vượt qua ngưỡng này trung bình các tháng đều ở mức cao, cụ thể là từ tháng $5-8$ số ngày có $\mathrm{HI}>39,4^{\circ} \mathrm{C}$ phổ biến từ $25-30$ ngày, tháng 4 phổ biến từ 10-20 ngày, và tháng 9 phổ biến từ 15-25 ngày (Hình 3 ). 


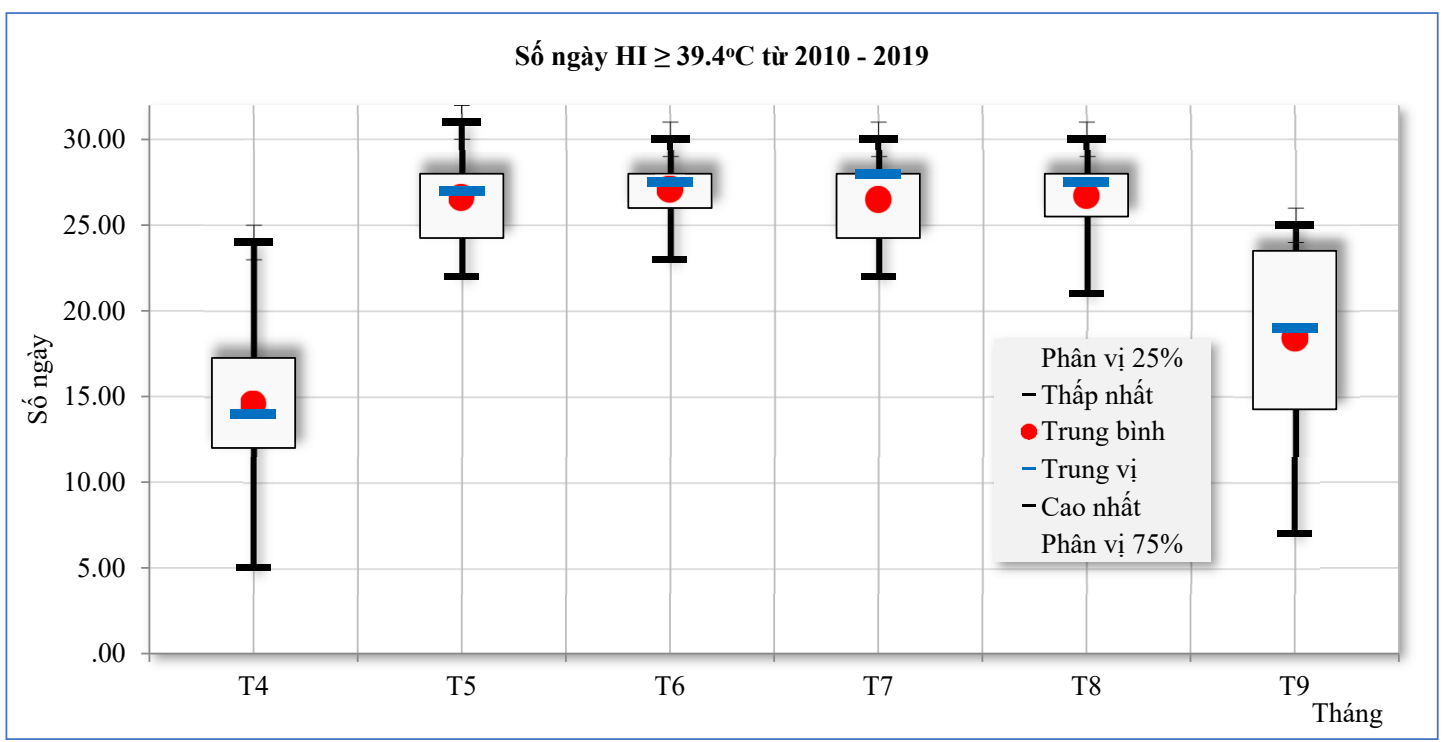

Hình 3. Số ngày HI vượt ngưỡng $39,4{ }^{\circ} \mathrm{C}$ trong thời kỳ 2010-2019.

Như vậy số ngày xảy ra $\mathrm{HI}>39,4{ }^{\circ} \mathrm{C}$ tại Quảng Nam dao động từ $25-30$ ngày từ tháng 5 đến tháng 8 , chiếm hầu như $100 \%$ cả tháng. Điều này chứng tỏ rằng ngưỡng cảnh báo $\mathrm{HI}$ nguy hiểm cho cộng đồng dân cư tại Quảng Nam phải cao hơn so với ngưỡng cảnh báo của NOAA, tức là mức cảnh báo nhiệt độ nguy hiểm đối với người dân Quảng Nam phải lớn hơn ngưỡng $39,4^{\circ} \mathrm{C}$.

\subsection{Xu thế biến đổi hệ số nhiệt du thùa giai đoạn 1979-2019}

Điều kiện để nắng nóng nguy hiểm xảy ra là khi có EHF dương và xảy ra liên tục từ ba ngày trở lên, vì vậy khi đánh giá được nắng nóng nguy hiểm sẽ phản ảnh được hệ số nhiệt dư thừa. Phân tích nắng nóng nguy hiểm từ năm 1980-2019 (Bảng 1) theo các thời đoạn 19801989, 1990-1999, 2000-2009, 2010-2019.

Bảng 1. Nắng nóng nguy hiểm trong 4 thập kỷ gần đây.

\begin{tabular}{cccccc}
\hline Thời gian & $\begin{array}{c}\text { Hệ số nhiệt } \\
\text { dư thừa } \\
\left({ }^{\circ} \mathbf{C}^{\mathbf{2}}\right)\end{array}$ & $\begin{array}{c}\text { Hệ số nhiệt } \\
\text { dư thừa lớn } \\
\text { nhất }\left({ }^{\circ} \mathbf{C}^{\mathbf{2}}\right)\end{array}$ & $\begin{array}{c}\text { Tổng } \\
\text { số đọ̣t } \\
\text { (đọ̣t) }\end{array}$ & $\begin{array}{c}\text { Số ngày của } \\
\text { đọ̣t nắng nóng nguy } \\
\text { hiểm dài nhất (ngày) }\end{array}$ & $\begin{array}{c}\text { Tổng số ngày xảy } \\
\text { ra nắng nóng } \\
\text { nguy hiểm (ngày) }\end{array}$ \\
\hline $1980-1989$ & 1,8 & 11,4 & 16 & 06 & 61 \\
$1990-1999$ & 1,1 & 7,8 & 10 & 06 & 37 \\
$2000-2009$ & 1,0 & 3,0 & 13 & 11 & 60 \\
$2010-2019$ & 1,0 & 7,8 & 29 & 22 & 175 \\
\hline
\end{tabular}

Trong 3 thập kỷ 1990-1999, 2000-2009, 2010-2019 hệ số nhiệt dư thừa trung bình năm trong các năm có nắng nóng nguy hiểm chỉ dao động quanh $1,0{ }^{\circ} \mathrm{C}^{2}$, và nhỏ hơn thập kỷ 1980-1989 tới $0,8^{\circ} \mathrm{C}^{2}$. Nhiệt dư thừa lớn nhất trong một đợt nắng nóng nguy hiểm của thập kỷ 1980-1989 lớn hơn 3,6 ${ }^{\circ} \mathrm{C}^{2}$ so với 2 thập kỷ 1990-1999 và 2010-2019, và lớn hơn thập kỷ 2000-2009 tới 8,4 ${ }^{\circ} \mathrm{C}^{2}$. Trong thập kỷ 2010-2019 có tổng số đợt, số ngày trong 01 đợt dài nhất và tổng số ngày xảy ra nắng nóng nguy hiểm tăng lên gấp 2 đến 3 lần so với 3 thập kỷ trước (Bảng 1).

Tổng số ngày xảy ra nắng nóng nguy hiểm trong năm, số ngày của đợt có nắng nóng nguy hiểm dài nhất và tổng số đợt nắng nóng nguy hiểm xảy ra trong năm của những năm gần đây tăng lên đáng kể. Và xu thế tăng lên trong tương lai đạt kết quả khá tin cậy (với $\mathrm{P}<$ $0,05)$. Kết quả được thể hiện trên các hình 4,5 và 6 . 


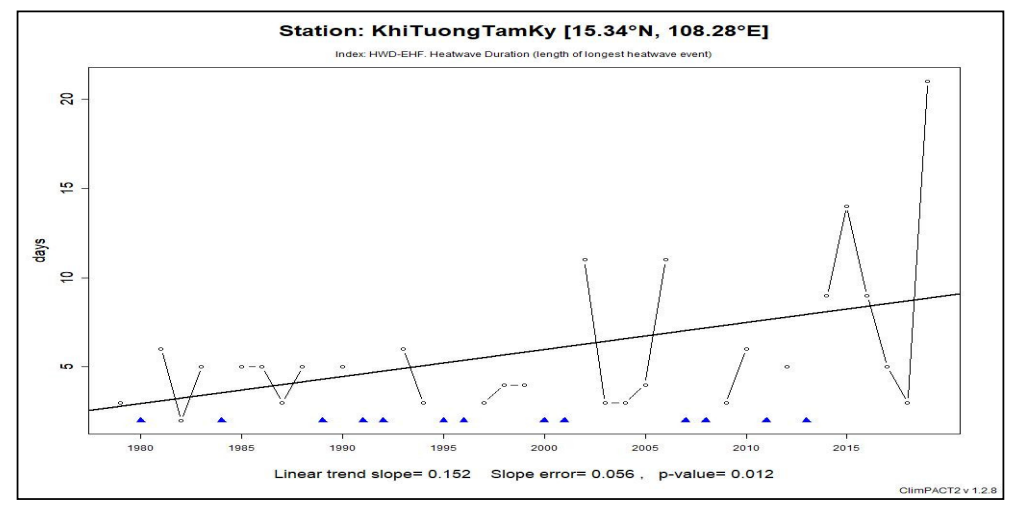

Hình 4. Xu thế biến đổi tổng số ngày của các đợt nắng nóng nguy hiểm dài nhất trong từng năm từ 1979-2019.

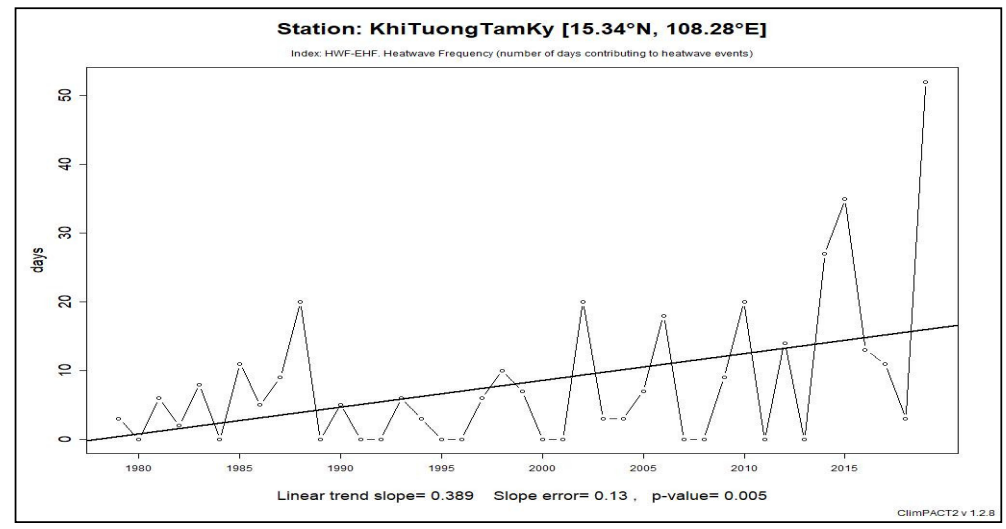

Hình 5. Tổng số ngày xuất hiện hiện tượng nắng nóng nguy hiểm thời kỳ 1979-2019.

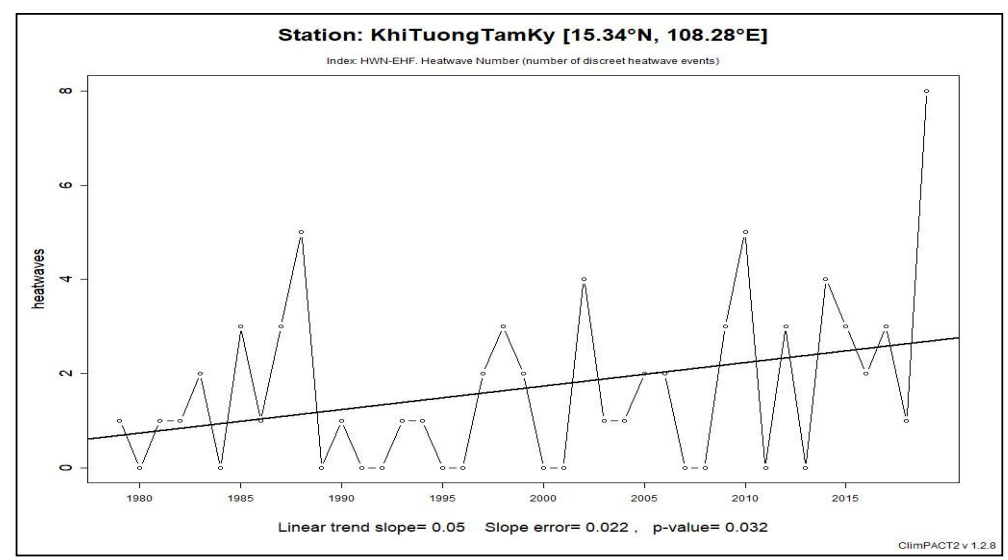

Hình 6. Số đợt nắng nóng nguy hiểm thời kỳ 1979-2019.

Như vậy trong thời gian gần đây nắng nóng nguy hiểm có xu hướng tăng về số đợt, số ngày trong mỗi đợt kéo dài hơn, và tổng số ngày của các đợt có nắng nóng nguy hiểm trong năm ngày càng nhiều hơn. Theo khuyến cáo của Tổ chức khí tượng thế giới lượng nhiệt dư thừa dương xảy ra liên tục và kéo dài sẽ ảnh hưởng lớn tới sức khỏe con người.

\section{3. Đánh giá mối liên hệ giữa HI, nắng nóng nguy hiểm và số lượng bệnh nhân}

Khi tác động của môi trường (nhiệt độ, độ ẩm) vượt quá sức chịu đựng của con người trong một thời gian thì các bệnh có liên quan đển hô hấp, tim mạch, cao huyết áp, hen suyễn, sốt, sốt xuất huyết, hay thậm chí là đột quỵ mới bắt đầu xuất hiện. Hình 7 minh họa số lượng 
bệnh nhân ở các bệnh viện tại Tam Kỳ trong tháng 6/2019, trong đó thời điểm xuất hiện hiện tượng nắng nóng nguy hiểm (heatwave) được minh họa bởi hình chữ nhật có viền đen, số lượng bệnh nhân tại các bệnh viện được thể hiện bởi các đường tương ứng chú giải trên đồ thị. Theo khảo sát của chúng tôi, việc đánh giá đánh giá tác động của nhiệt độ cảm nhận tới sức khỏe theo từng ngày gặp nhiều khó khăn bởi một số nguyên nhân khách quan như sau. Khi bị các bệnh nói trên tâm lý bệnh nhân thường sẽ tự điều trị bằng cách mua thuốc uống trước chứ chưa tới bệnh viện để khám (ngoài những bệnh nặng nhất thiết phải tới bệnh viện như đột quy, sốt cao co giật,...), chỉ khi nào bệnh chuyển biến xấu hơn thì mới tới các trung tâm, bệnh viện để khám chữa bệnh. Ngoài ra, tâm lý ngại đi khám chữa bệnh vào thứ 7 , chủ nhật, nên lượng bệnh nhân khám chữa bệnh trong ngày thứ 7 và chủ nhật khá ít, sang tuần mới (thứ 2) thì số lượng bệnh nhân tại các cơ sở khám chữa bệnh lại tăng vọt. Số liệu khám chữa bệnh hàng năm ở các bệnh viện sẽ có sự dao dộng (tăng, giảm về số lượng người bệnh), ví dụ như khi có sự thay đổi về địa điểm khám chữa bệnh trong thẻ bảo hiểm y tế từ bệnh viện này đến bệnh viện kia. Và do đó, nếu chỉ dựa vào số liệu bệnh nhân tại các bệnh viện thì không dễ dàng đánh giá đúng được tác động của nắng nóng nguy hiểm.

\subsubsection{Mối liên hệ giữa $\mathrm{HI}$ và nắng nóng nguy hiểm}

Từ năm 2017 đến 2019 xảy ra 12 đợt nắng nóng nguy hiểm, với tổng số ngày là 68 ngày, trong đó đợt ngắn nhất có 3 ngày, đợt dài nhất có 22 ngày từ $09-30 / 6 / 2019$. Ngày có HI nhỏ nhất là $42,0{ }^{\circ} \mathrm{C}$ trong đợt $15-19 / 8 / 2019$ và ngày có $\mathrm{HI}$ lớn nhất là $52,9{ }^{\circ} \mathrm{C}$ trong đợt $17-$ $21 / 5 / 2019$ (chi tiết bảng 2 ). Như vậy trong tất cả các đợt xảy ra nắng nóng nguy hiểm từ 2017-2019 đều có $\mathrm{HI} \geq 42.0^{\circ} \mathrm{C}$ và cao hơn ngưỡng cảnh báo nguy hiểm của NOAA dành cho người dân Mỹ.

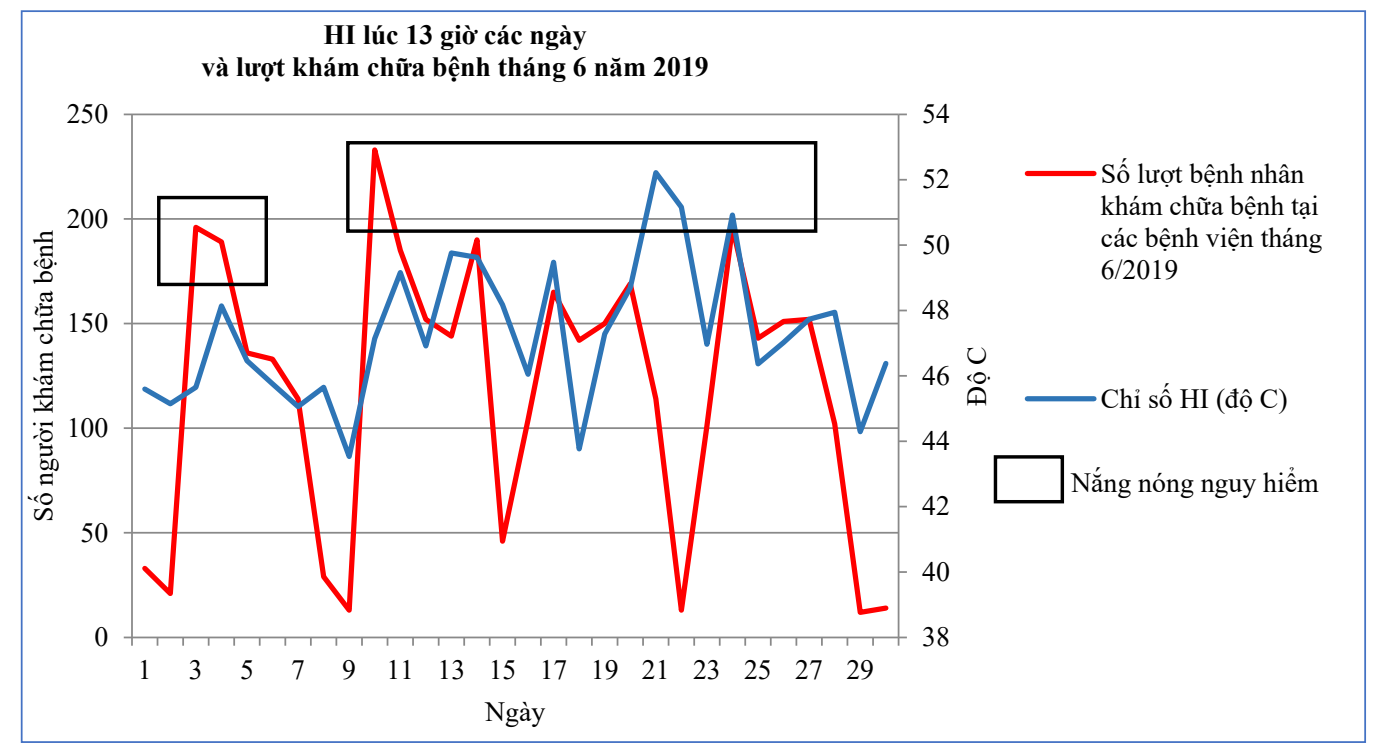

Hình 7. HI lúc 13 giờ các ngày và số lượt khám chữa bệnh tháng 6/2019.

Bảng 2. HI và nắng nóng nguy hiểm từ năm 2017-2019.

\begin{tabular}{cccc}
\hline Đọtt & $\begin{array}{c}\text { Thời gian có xảy ra } \\
\text { nắng nóng nguy hiểm }\end{array}$ & $\begin{array}{c}\text { HI } \\
\text { thấp nhất }\left({ }^{\circ} \mathbf{C}\right)\end{array}$ & $\begin{array}{c}\text { HI } \\
\text { cao nhất }\left({ }^{\circ} \mathbf{C}\right)\end{array}$ \\
\hline 1 & $02-06 / 6 / 2017$ & 44,4 & 49,2 \\
2 & $19-21 / 6 / 2017$ & 42,4 & 45,3 \\
3 & $01-03 / 8 / 2017$ & 47,4 & 48,5 \\
4 & $20-22 / 8 / 2018$ & 46,7 & 49,4 \\
\hline
\end{tabular}




\begin{tabular}{cccc}
\hline Đọ̀t & $\begin{array}{c}\text { Thời gian có xảy ra } \\
\text { nắng nóng nguy hiểm }\end{array}$ & $\begin{array}{c}\text { HI } \\
\text { thấp nhất }\left({ }^{\circ} \mathbf{C}\right)\end{array}$ & $\begin{array}{c}\text { HI } \\
\text { cao nhất }\left({ }^{\circ} \mathbf{C}\right)\end{array}$ \\
\hline 5 & $19-21 / 4 / 2019$ & 47,3 & 48,9 \\
6 & $05-08 / 5 / 2019$ & 42,9 & 48,0 \\
7 & $17-21 / 5 / 2019$ & 44,9 & 52,9 \\
8 & $04-06 / 6 / 2019$ & 45,8 & 48,1 \\
9 & $09-30 / 6 / 2019$ & 43,5 & 52,2 \\
10 & $07-15 / 7 / 2019$ & 45,1 & 50,0 \\
11 & $19-21 / 7 / 2019$ & 45,8 & 46,9 \\
12 & $15-19 / 8 / 2019$ & 42,0 & 48,5 \\
\hline
\end{tabular}

\subsubsection{Mối liên hệ giữa $\mathrm{HI}$ và số lượt bệnh nhân}

a. Đánh giá theo tháng

Phân tích số liệu y tế cho ta thấy được trong các tháng 4-9 trong 3 năm gần đây, thì số lượng bệnh nhân tăng vào tháng 5 và tháng $7-8$, giảm nhẹ vào tháng 6,9 (chi tiết hình 8,9 và 10 ). Trong các tháng $5-8, \mathrm{HI}$ có giá trị lớn và đều dao động từ $25-30$ ngày (chi tiết mục 3.1). Qua tính toán chúng tôi đề xuất ngưỡng $\mathrm{HI} \geq 41,0{ }^{\circ} \mathrm{C}$ để đánh giá sức khỏe người dân tại Quảng Nam.

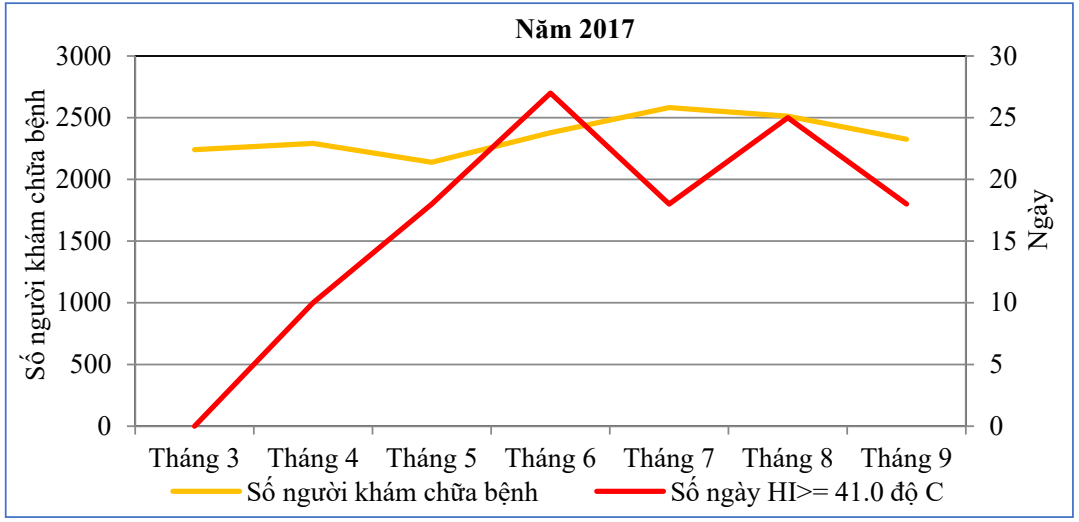

Hình 8. Số người khám chữa bệnh và số ngày $\mathrm{HI} \geq 41,0{ }^{\circ} \mathrm{C}$ trong năm 2017.

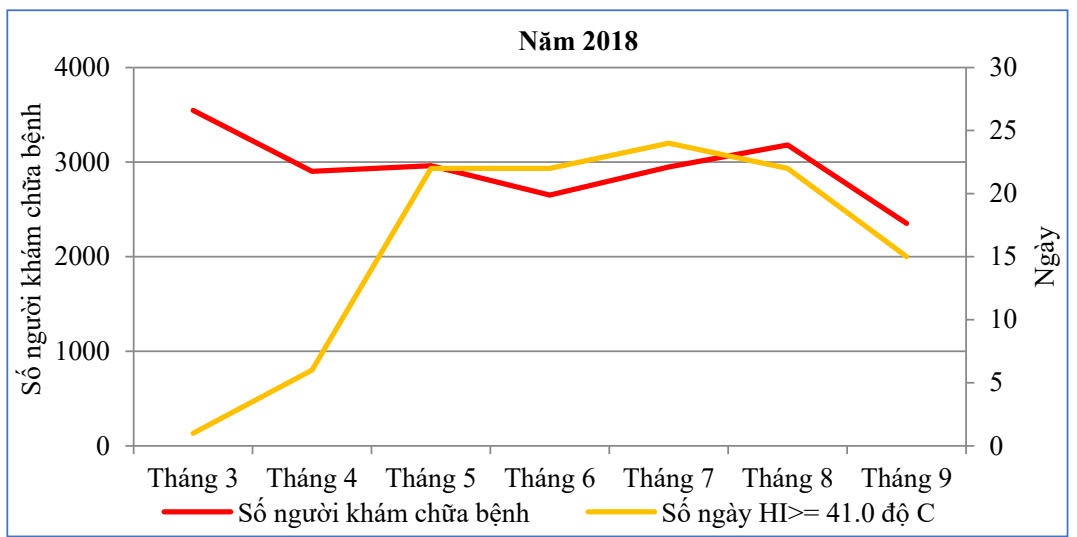

Hình 9. Số người khám chữa bệnh và số ngày $\mathrm{HI} \geq 41,0{ }^{\circ} \mathrm{C}$ trong năm 2018 . 


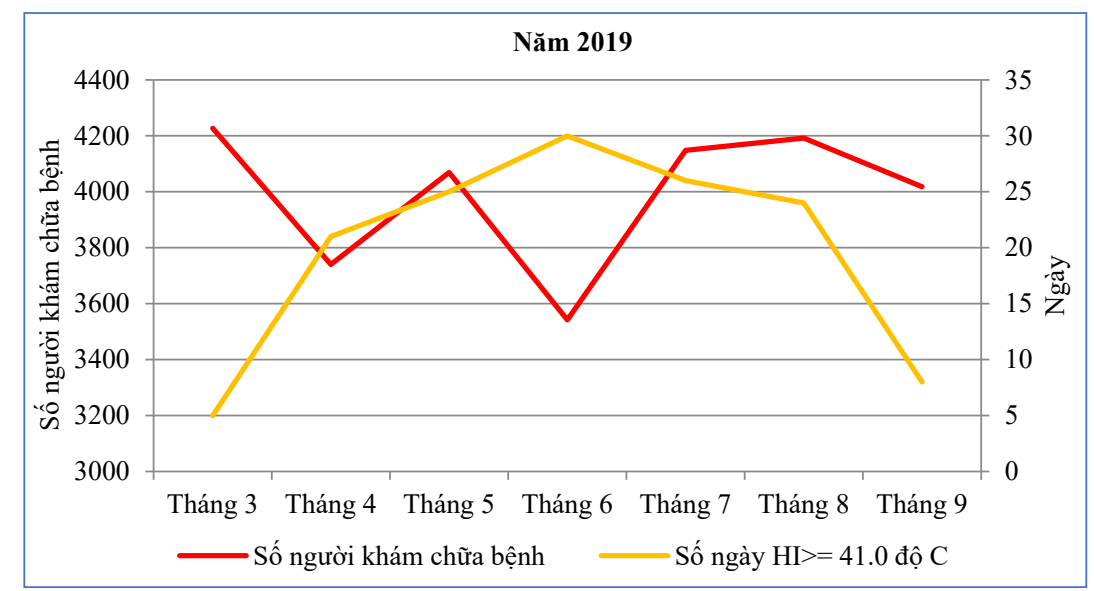

Hình 10. Số người khám chữa bệnh và số ngày $\mathrm{HI} \geq 41,0{ }^{\circ} \mathrm{C}$ trong năm 2019.

\section{b. Đánh giá theo số liệu ngày}

Qua quá trình tính toán hồi qui, hay so sánh từng ngày giữa chỉ số HI với số lượng bệnh nhân ở các bệnh viện khác nhau vào các ngày có nắng nóng nguy hiểm để tìm mối quan hệ giữa chúng tuy nhiên do một số tình huống khách quan trình bày tại Mục 3.3 nên việc đánh giá theo từng ngày gặp nhiều khó khăn, hầu như không có sự tương quan hoặc tương quan rất thấp (giữa $\mathrm{HI}$ và số lượng bệnh nhân).

c. Đánh giá, phân tích HI với số lượt bệnh nhi trong những đợt có nắng nóng nguy hiểm

Như phân tích tại Mục 3.3 giữa số liệu HI và số lượt bệnh nhi (trẻ sơ sinh đến 15 tuổi) khám chữa bệnh trong thời gian có hiện tượng nắng nóng nguy hiểm sức khỏe xảy ra có mối tương quan rất thấp, với hệ số tương quan bội (multiple $R$ ) là 0,073 và hệ số xác định ( $R$ Square) là 0,005 . Chúng tôi cũng đã xây dựng phương trình hồi qui tính lượt bệnh nhi với nhân tố là HI với độ trễ là 3 ngày, tuy nhiên hệ số tương quan bội và hệ số xác định rất thấp lần lượt là 0,15 và 0,02 .

Trong năm 2019 có 08 đợt nắng nóng nguy hiểm, số ngày của các đợt nắng nóng nguy hiểm và $\mathrm{HI}$ cũng cao hơn 2017-2018 (Bảng 2), tuy nhiên qua số liệu khám chữa bệnh nhi từng ngày, trung bình mỗi ngày có xảy ra nắng nóng nguy hiểm thì số lượng khám chữa bệnh nhi năm 2019 lại nhỏ hơn 2017 và 2018 cụ thể như sau: năm 2017 là 12,3 lượt/ngày, 2018 là 15,0 lượt/ngày, 2019 là 10,8 lượt/ngày. Trung bình số lượt khám chữa bệnh nhi từng tháng từ tháng 4-9 năm 2019 cũng thấp hơn 2017-2018 (Bảng 3).

Bảng 3. Lượt khám chữa bệnh trung bình tháng 4-9 từ năm 2017 đến 2019.

\begin{tabular}{cccccccc}
\hline Năm & T4 & T5 & T6 & T7 & T8 & T9 & TB \\
\hline 2017 & 15,1 & 11,4 & 12,2 & 14,4 & 15,3 & 14,9 & 13,9 \\
2018 & 14,8 & 11,3 & 10,3 & 11,2 & 13,7 & 13,0 & 12,4 \\
2019 & 12,4 & 11,1 & 10,4 & 8,7 & 9,6 & 15,5 & 11,3 \\
\hline
\end{tabular}

Số liệu cho thấy nắng nóng nguy hiểm tuy tăng về đợt, số ngày trong các đợt và $\mathrm{HI}$ cao trong năm 2019 nhưng số lượng bệnh nhi khám chữa bệnh lại giảm. Điều này liên quan tới một số yếu tố khách quan như dịch vụ và chất lượng y tế nâng cao....và do đó cũng khó có thể khẳng định số lượng bệnh nhi giảm trong thời kỳ nắng nóng nguy hiểm trong những năm gần đây. Như vậy, cần tiếp tục nghiên cứu, đánh giá, xem xét lại kết luận này một cách đầy đủ hơn trong tương lai khi có nguồn số liệu khám chữa bệnh nhi đầy đủ và dài hơn. 


\subsection{Xây dưng bộ chỉ tiêu nhiệt ẩm ảnh hưởng tới sức khỏe một số cộng đồng dân cu}

Qua phân tích, đánh giá mối liên quan giữa $\mathrm{HI}$, các đợt nắng nóng nguy hiểm và số lượng bệnh nhân từ 2017-2019 ở mục 3.3.1, 3.3.2 và tham khảo ngưỡng cảnh báo của NOAA, chúng tôi đề xuất các ngưỡng cảnh báo như sau:

+ Chọn ngưỡng $32,8^{\circ} \mathrm{C}<\mathrm{HI}<41,0^{\circ} \mathrm{C}$ là ngưỡng cảnh báo cần thận trọng; tuy nhiên đối với nhóm người tiếp xúc trực tiếp dưới ánh nắng mặt trời có thể nâng mức cảnh báo là nguy hiểm.

+ Mức nguy hiểm từ $41,0^{\circ} \mathrm{C} \leq \mathrm{HI} \leq 51,0^{\circ} \mathrm{C}$

+ Mức cực kỳ nguy hiểm $\mathrm{HI}>51,0^{\circ} \mathrm{C}$

Tại Quảng Nam, nơi luôn có nền nhiệt độ trung bình năm cao, các dịch bệnh có điều kiện phát triển, trẻ sơ sinh và trẻ dưới 15 tuổi là nhóm cộng đồng có sức đề kháng yếu hơn người trưởng thành; họ dễ bị lây nhiễm và mắc phải các dịch bệnh liên quan. Vì vậy nghiên cứu này đề xuất ngưỡng nhiệt độ cảm nhận nguy hiểm đối với bệnh nhi (trẻ sơ sinh đến 15 tuổi) thấp hơn những người từ 15 tuổi trở lên từ 1 đến 2 độ.

Qua những phân tích trên, nghiên cứu này đề xuất ngưỡng $\mathrm{HI}$ cảnh báo cho cộng đồng dân cư trên 15 tuổi (Bảng 4), trẻ sơ sinh và trẻ nhỏ dưới 15 tuổi (Bảng 5) dưới đây.

Bảng 4. Ngưỡng HI đề xuất cảnh báo cho cộng đồng dân cư trên 15 tuổi.

\begin{tabular}{|c|c|c|c|c|c|c|c|c|c|c|c|c|c|c|c|}
\hline 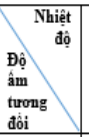 & $28^{\circ} \mathrm{C}$ & $29^{\circ} \mathrm{C}$ & $30^{\circ} \mathrm{C}$ & $31^{\circ} \mathrm{C}$ & $32^{\circ} \mathrm{C}$ & $3^{\circ} \mathrm{C}$ & $34^{\circ} \mathrm{C}$ & $36^{\circ} \mathrm{C}$ & $37^{\circ} \mathrm{C}$ & $38^{\circ} \mathrm{C}$ & $39^{\circ} \mathrm{C}$ & $40^{\circ} \mathrm{C}$ & $41^{\circ} \mathrm{C}$ & $42^{\circ} \mathrm{C}$ & $43^{\circ} \mathrm{C}$ \\
\hline $40 \%$ & $27^{\circ} \mathrm{C}$ & $28^{\circ} \mathrm{C}$ & $29^{\circ} \mathrm{C}$ & $31^{\circ} \mathrm{C}$ & $33^{\circ} \mathrm{C}$ & $34^{\circ} \mathrm{C}$ & $36^{\circ} \mathrm{C}$ & $38^{\circ} \mathrm{C}$ & $41^{\circ} \mathrm{C}$ & $43^{\circ} \mathrm{C}$ & $46^{\circ} \mathrm{C}$ & $48^{\circ} \mathrm{C}$ & $51^{\circ} \mathrm{C}$ & $54^{\circ} \mathrm{C}$ & $58^{\circ} \mathrm{C}$ \\
\hline $45 \%$ & $28^{\circ} \mathrm{C}$ & $29^{\circ} \mathrm{C}$ & $31^{\circ} \mathrm{C}$ & $32^{\circ} \mathrm{C}$ & $34^{\circ} \mathrm{C}$ & $36^{\circ} \mathrm{C}$ & $38^{\circ} \mathrm{C}$ & $40^{\circ} \mathrm{C}$ & $43^{\circ} \mathrm{C}$ & $46^{\circ} \mathrm{C}$ & $48^{\circ} \mathrm{C}$ & $51^{\circ} \mathrm{C}$ & $54^{\circ} \mathrm{C}$ & $58^{\circ} \mathrm{C}$ & \\
\hline $\mathbf{5 0 \%}$ & $28^{\circ} \mathrm{C}$ & $29^{\circ} \mathrm{C}$ & $31^{\circ} \mathrm{C}$ & $33^{\circ} \mathrm{C}$ & $35^{\circ} \mathrm{C}$ & $37^{\circ} \mathrm{C}$ & $39^{\circ} \mathrm{C}$ & $42^{\circ} \mathrm{C}$ & $45^{\circ} \mathrm{C}$ & $48^{\circ} \mathrm{C}$ & $51^{\circ} \mathrm{C}$ & $55^{\circ} \mathrm{C}$ & $58^{\circ} \mathrm{C}$ & & \\
\hline $\mathbf{5 5} \%$ & $29^{\circ} \mathrm{C}$ & $30^{\circ} \mathrm{C}$ & $32^{\circ} \mathrm{C}$ & $34^{\circ} \mathrm{C}$ & $36^{\circ} \mathrm{C}$ & $38^{\circ} \mathrm{C}$ & $41^{\circ} \mathrm{C}$ & $44^{\circ} \mathrm{C}$ & $47^{\circ} \mathrm{C}$ & $51^{\circ} \mathrm{C}$ & $54^{\circ} \mathrm{C}$ & $58^{\circ} \mathrm{C}$ & & & \\
\hline $60 \%$ & $29^{\circ} \mathrm{C}$ & $31^{\circ} \mathrm{C}$ & $33^{\circ} \mathrm{C}$ & $35^{\circ} \mathrm{C}$ & $38^{\circ} \mathrm{C}$ & $41^{\circ} \mathrm{C}$ & $43^{\circ} \mathrm{C}$ & $47^{\circ} \mathrm{C}$ & $51^{\circ} \mathrm{C}$ & $54^{\circ} \mathrm{C}$ & $58^{\circ} \mathrm{C}$ & & & & \\
\hline $65 \%$ & $29^{\circ} \mathrm{C}$ & $32^{\circ} \mathrm{C}$ & $34^{\circ} \mathrm{C}$ & $37^{\circ} \mathrm{C}$ & $39^{\circ} \mathrm{C}$ & $42^{\circ} \mathrm{C}$ & $46^{\circ} \mathrm{C}$ & $49^{\circ} \mathrm{C}$ & $53^{\circ} \mathrm{C}$ & $58^{\circ} \mathrm{C}$ & & & & & \\
\hline $70 \%$ & $30^{\circ} \mathrm{C}$ & $32^{\circ} \mathrm{C}$ & $35^{\circ} \mathrm{C}$ & $38^{\circ} \mathrm{C}$ & $41^{\circ} \mathrm{C}$ & $44^{\circ} \mathrm{C}$ & $48^{\circ} \mathrm{C}$ & $52^{\circ} \mathrm{C}$ & $57^{\circ} \mathrm{C}$ & & & & & & \\
\hline $75 \%$ & $31^{\circ} \mathrm{C}$ & $33^{\circ} \mathrm{C}$ & $36^{\circ} \mathrm{C}$ & $39^{\circ} \mathrm{C}$ & $43^{\circ} \mathrm{C}$ & $47^{\circ} \mathrm{C}$ & $51^{\circ} \mathrm{C}$ & $56^{\circ} \mathrm{C}$ & & & & & & & \\
\hline $80 \%$ & $32^{\circ} \mathrm{C}$ & $34^{\circ} \mathrm{C}$ & $38^{\circ} \mathrm{C}$ & $41^{\circ} \mathrm{C}$ & $45^{\circ} \mathrm{C}$ & $49^{\circ} \mathrm{C}$ & $54^{\circ} \mathrm{C}$ & & & & & & & & \\
\hline $85 \%$ & $32^{\circ} \mathrm{C}$ & $36^{\circ} \mathrm{C}$ & $39^{\circ} \mathrm{C}$ & $43^{\circ} \mathrm{C}$ & $47^{\circ} \mathrm{C}$ & $52^{\circ} \mathrm{C}$ & $57^{\circ} \mathrm{C}$ & & & & & & & & \\
\hline $90 \%$ & $33^{\circ} \mathrm{C}$ & $37^{\circ} \mathrm{C}$ & $41^{\circ} \mathrm{C}$ & $45^{\circ} \mathrm{C}$ & $50^{\circ} \mathrm{C}$ & $55^{\circ} \mathrm{C}$ & & & & & & & & & \\
\hline $95 \%$ & $34^{\circ} \mathrm{C}$ & $38^{\circ} \mathrm{C}$ & $42^{\circ} \mathrm{C}$ & $47^{\circ} \mathrm{C}$ & $53^{\circ} \mathrm{C}$ & & & & & & & & & & \\
\hline $100 \%$ & $35^{\circ} \mathrm{C}$ & $39^{\circ} \mathrm{C}$ & 44 & 45 & $56^{\circ} \mathrm{C}$ & & & & & & & & & & \\
\hline
\end{tabular}

Thận trọng $\quad \square$ Nguy hiểm Cực kỳ nguy hiểm

Bảng 5. Ngưỡng HI đề xuất cảnh báo cho trẻ sơ sinh và trẻ nhỏ dưới 15 tuổi.

\begin{tabular}{|c|c|c|c|c|c|c|c|c|c|c|c|c|c|c|c|c|}
\hline 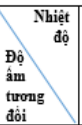 & $27^{\circ} \mathrm{C}$ & $8^{\circ} \mathrm{C}$ & $29^{\circ} \mathrm{C}$ & $30^{\circ} \mathrm{C}$ & $31^{\circ} \mathrm{C}$ & $32^{\circ} \mathrm{C}$ & $3^{\circ} \mathrm{C}$ & $34^{\circ} \mathrm{C}$ & $36^{\circ} \mathrm{C}$ & $37^{\circ} \mathrm{C}$ & $38^{\circ} \mathrm{C}$ & $39^{\circ} \mathrm{C}$ & $40^{\circ} \mathrm{C}$ & $41^{\circ} \mathrm{C}$ & $42^{\circ} \mathrm{C}$ & $43^{\circ} \mathrm{C}$ \\
\hline $40 \%$ & $27^{\circ} \mathrm{C}$ & $27^{\circ} \mathrm{C}$ & $28^{\circ} \mathrm{C}$ & $29^{\circ} \mathrm{C}$ & $31^{\circ} \mathrm{C}$ & $33^{\circ} \mathrm{C}$ & $34^{\circ} \mathrm{C}$ & $36^{\circ} \mathrm{C}$ & $38^{\circ} \mathrm{C}$ & $41^{\circ} \mathrm{C}$ & $43^{\circ} \mathrm{C}$ & $46^{\circ} \mathrm{C}$ & $48^{\circ} \mathrm{C}$ & $51^{\circ} \mathrm{C}$ & $54^{\circ} \mathrm{C}$ & $58^{\circ} \mathrm{C}$ \\
\hline $45 \%$ & $27^{\circ} \mathrm{C}$ & $28^{\circ} \mathrm{C}$ & $29^{\circ} \mathrm{C}$ & $31^{\circ} \mathrm{C}$ & $32^{\circ} \mathrm{C}$ & $34^{\circ} \mathrm{C}$ & $36^{\circ} \mathrm{C}$ & $38^{\circ} \mathrm{C}$ & $40^{\circ} \mathrm{C}$ & $43^{\circ} \mathrm{C}$ & $46^{\circ} \mathrm{C}$ & $48^{\circ} \mathrm{C}$ & $51^{\circ} \mathrm{C}$ & $54^{\circ} \mathrm{C}$ & $58^{\circ} \mathrm{C}$ & \\
\hline $\mathbf{5 0} \%$ & $27^{\circ} \mathrm{C}$ & $28^{\circ} \mathrm{C}$ & $29^{\circ} \mathrm{C}$ & $31^{\circ} \mathrm{C}$ & $33^{\circ} \mathrm{C}$ & $35^{\circ} \mathrm{C}$ & $37^{\circ} \mathrm{C}$ & $39^{\circ} \mathrm{C}$ & $42^{\circ} \mathrm{C}$ & $45^{\circ} \mathrm{C}$ & $48^{\circ} \mathrm{C}$ & $51^{\circ} \mathrm{C}$ & $55^{\circ} \mathrm{C}$ & $58^{\circ} \mathrm{C}$ & & \\
\hline $\mathbf{5 5} \%$ & $27^{\circ} \mathrm{C}$ & $29^{\circ} \mathrm{C}$ & $30^{\circ} \mathrm{C}$ & $32^{\circ} \mathrm{C}$ & $34^{\circ} \mathrm{C}$ & $36^{\circ} \mathrm{C}$ & $38^{\circ} \mathrm{C}$ & $41^{\circ} \mathrm{C}$ & $44^{\circ} \mathrm{C}$ & $47^{\circ} \mathrm{C}$ & $51^{\circ} \mathrm{C}$ & $54^{\circ} \mathrm{C}$ & $58^{\circ} \mathrm{C}$ & & & \\
\hline $60 \%$ & $28^{\circ} \mathrm{C}$ & $29^{\circ} \mathrm{C}$ & $31^{\circ} \mathrm{C}$ & $33^{\circ} \mathrm{C}$ & $35^{\circ} \mathrm{C}$ & $38^{\circ} \mathrm{C}$ & $41^{\circ} \mathrm{C}$ & $43^{\circ} \mathrm{C}$ & $47^{\circ} \mathrm{C}$ & $51^{\circ} \mathrm{C}$ & $54^{\circ} \mathrm{C}$ & $58^{\circ} \mathrm{C}$ & & & & \\
\hline $65 \%$ & $28^{\circ} \mathrm{C}$ & $29^{\circ} \mathrm{C}$ & $32^{\circ} \mathrm{C}$ & $34^{\circ} \mathrm{C}$ & $37^{\circ} \mathrm{C}$ & $39^{\circ} \mathrm{C}$ & $42^{\circ} \mathrm{C}$ & $46^{\circ} \mathrm{C}$ & $49^{\circ} \mathrm{C}$ & $53^{\circ} \mathrm{C}$ & $58^{\circ} \mathrm{C}$ & & & & & \\
\hline $70 \%$ & $28^{\circ} \mathrm{C}$ & $30^{\circ} \mathrm{C}$ & $32^{\circ} \mathrm{C}$ & $35^{\circ} \mathrm{C}$ & $38^{\circ} \mathrm{C}$ & $41^{\circ} \mathrm{C}$ & $44^{\circ} \mathrm{C}$ & $48^{\circ} \mathrm{C}$ & $52^{\circ} \mathrm{C}$ & $57^{\circ} \mathrm{C}$ & & & & & & \\
\hline $75 \%$ & $29^{\circ} \mathrm{C}$ & $31^{\circ} \mathrm{C}$ & $33^{\circ} \mathrm{C}$ & $36^{\circ} \mathrm{C}$ & $39^{\circ} \mathrm{C}$ & $43^{\circ} \mathrm{C}$ & $47^{\circ} \mathrm{C}$ & $51^{\circ} \mathrm{C}$ & $56^{\circ} \mathrm{C}$ & & & & & & & \\
\hline $80 \%$ & $29^{\circ} \mathrm{C}$ & $32^{\circ} \mathrm{C}$ & $34^{\circ} \mathrm{C}$ & $38^{\circ} \mathrm{C}$ & $41^{\circ} \mathrm{C}$ & $45^{\circ} \mathrm{C}$ & $49^{\circ} \mathrm{C}$ & $54^{\circ} \mathrm{C}$ & & & & & & & & \\
\hline $85 \%$ & $29^{\circ} \mathrm{C}$ & $32^{\circ} \mathrm{C}$ & $36^{\circ} \mathrm{C}$ & $39^{\circ} \mathrm{C}$ & $43^{\circ} \mathrm{C}$ & $47^{\circ} \mathrm{C}$ & $52^{\circ} \mathrm{C}$ & $57^{\circ} \mathrm{C}$ & & & & & & & & \\
\hline $90 \%$ & $30^{\circ} \mathrm{C}$ & $33^{\circ} \mathrm{C}$ & $37^{\circ} \mathrm{C}$ & $41^{\circ} \mathrm{C}$ & $45^{\circ} \mathrm{C}$ & $50^{\circ} \mathrm{C}$ & $55^{\circ} \mathrm{C}$ & & & & & & & & & \\
\hline $95 \%$ & $30^{\circ} \mathrm{C}$ & $34^{\circ} \mathrm{C}$ & $38^{\circ} \mathrm{C}$ & $42^{\circ} \mathrm{C}$ & $47^{\circ} \mathrm{C}$ & $53^{\circ} \mathrm{C}$ & & & & & & & & & & \\
\hline $100 \%$ & $31^{\circ} \mathrm{C}$ & $35^{\circ} \mathrm{C}$ & $39^{\circ} \mathrm{C}$ & $44^{\circ} \mathrm{C}$ & $49^{\circ} \mathrm{C}$ & $56^{\circ} \mathrm{C}$ & & & & & & & & & & \\
\hline
\end{tabular}




\section{Kết luận}

Thuật ngữ nắng nóng nguy hiểm (heatwave) chỉ hiện tượng nắng nóng xảy ra trong ít nhất ba ngày liên tiếp và đạt mức phân vị $90 \%$ được lần đầu giới thiệu và sử dụng trong nghiên cứu này. Trong bốn thập kỷ gần đây (1979-2019) nhiệt độ cảm nhận HI có biên độ dao động lớn. Đáng chú ý trong thập kỷ 2010-2019, hiện tượng nắng nóng nguy hiểm có xu hướng gia tăng về số đợt, số ngày và thời gian trung bình của từng đợt nắng nóng nguy hiểm tăng lên. Dựa vào phân tích nhiệt độ cảm nhận, hiện tượng nắng nóng nguy hiểm, và kết hợp với số liệu y tế tại khu vực thành phố Tam Kỳ nghiên cứu này đã đề xuất các ngưỡng cảnh báo nhiệt độ cảm nhận HI lần lượt là $32,8{ }^{\circ} \mathrm{C}, 41,0^{\circ} \mathrm{C}$ và $51,0^{\circ} \mathrm{C}$ ứng với ngưỡng cảnh báo thận trọng, nguy hiểm và cực kỳ nguy hiểm tới sức khỏe người dân Quảng Nam. Đối với trẻ sơ sinh và trẻ nhỏ dưới 15 tuổi, ngưỡng cảnh báo trên giảm ở mức thấp hơn từ 1 đến 2 độ.

Đóng góp của tác giả: Xây dựng ý tưởng nghiên cứu: N.C.T., N.Đ.Q.; Lựa chọn phương pháp nghiên cứu: N.C.T., N.Đ.Q.; Xử lý số liệu: N.C.T; Viết bản thảo bài báo: N.C.T., N.Đ.Q.; Chỉnh sửa bài báo: N.C.T., N.Đ.Q.

Lời cảm ơn: Bài báo là một phần kết quả trong luận văn thạc sĩ khí tượng của Nguyễn Công Tài với đề tài "Nghiên cứu xây dựng bộ chỉ tiêu nhiệt ẩm ảnh hưởng tới sức khỏe một số cộng đồng dân cư tại Quảng Nam”, bảo vệ tại Hội đồng Trường Đại học Tài nguyên và Môi trường Hà Nội, tháng 6/2020.

Lời cam đoan: Tập thể tác giả cam đoan bài báo này là công trình nghiên cứu của tập thể tác giả, chưa được công bố ở đâu, không được sao chép từ những nghiên cứu trước đây; không có sự tranh chấp lợi ích trong nhóm tác giả.

\section{Tài liệu tham khảo}

1. Rothfusz, L.P. The Heat Index "Equation" (or, More Than You Ever Wanted to Know About Heat Index). Technical Attachment. Scientific Services Division, NWS Southern Region Headquarters, Fort Worth, TX. SR 90-23, 7/1/90, 1990.

2. Nairn, J.R.; Fawcett, R.G. The Excess Heat Factor: A Metric for Heatwave Intensity and Its Use in Classifying Heatwave Severity. Int. J. Environ. Res. Public Health 2014, 12, 227-253. https://doi.org/10.3390/ijerph120100227.

3. Eun-Soon, I.; Pal, J.S.; Elfatih, A.; Eltahir, B. Deadly heat waves projected in the densely populated agricultural regions of South Asia. Sci. Adv. 2017, 3, e1603322. https://doi.org/10.1126/sciadv.1603322.

4. Wu, J.; Gao, X.; Giorgi, F.; Chen, D. Changes of effective temperature and cold/hot days in late decades over China based on a high resolution gridded observation dataset. Int. J. Climatol. 2017, 37, 788-800. https://doi.org/10.1002/joc.5038.

5. Opitz-Stapleton, S.; Sabbag, L.; Hawley, K.; Tran, P.; Hoang, L.; Nguyen, P.H. Heat index trends and climate change implications for occupational heat exposure in Da Nang, Vietnam. Clim. Serv. 2016, 2-3, 41-51.

6. Thảo, P.T.M.; Linh, P.T. Đánh giá tác động của biến đổi khí hậu tới sức khỏe cộng đồng tại huyện Giao Thủy, tỉnh Nam Định và đề xuất giải pháp thích ứng. Tạp chí Khoa học Trường Đại học Cần Tho 2017, 2, 113-119.

7. Quyền, N.H. và cs Nghiên cứu xác định bộ chỉ tiêu và xây dựng mô hình khí hậu phục vụ cảnh báo nguy cơ phát sinh dịch bệnh trên người ở một số tỉnh vùng miền núi phía Tây Bắc, 2019. 


\section{A study on temperature-humidity criteria affecting to health at some communities in Quang Nam Province}

\section{Nguyen Cong Tai ${ }^{1}$, Nguyen Dang Quang ${ }^{2}$}

${ }^{1}$ Quang Nam Hydro-Meteorological Services; taikttvqnam@gmail.com

${ }^{2}$ Center for Hydro-Meteorological Technology Application; quangvnes@gmail.com

Abstract: This study assesses the trend of Heat Index and Excess Heat Factor by using meteorological data in Quang Nam from 1979 to 2019. In combination with local health data, the temperature-humidity threshold possibly affecting the health of some communities in Quang Nam is classified. This is one of the first studies towards the weather information application serving the public health in Vietnam.

Keywords: Heat Index; Excess Heat Factor; Weather-Health Application. 